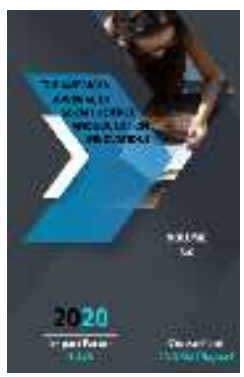

\title{
Importance Of Paralinguistic Features In Communication And Their Theoretical Study
}

\author{
Feruzabonu Temurqizi Temirova \\ Chair Of "Uzbek Language And Literature" Almalyk Branch of Tashkent State Technical \\ University Named After Islam Karimov, Uzbeskitan
}

Journal Website: http://usajournalshub.c om/index,php/tajssei

\section{ABSTRACT}

Noverbal communication plays an important role in the communication process, and it is in the process of conversation plays an important role in order to increase the effectiveness of speech. Psychology, cultural studies, and sociology are also important in the study of this type of communication. After all, when approaching an event, people approach it primarily on the basis of their worldview, position in society and the environment in which they live, which indicates that the above sciences are inextricably linked with linguistics.

\section{KEYWORDS}

Paralinguistic, information-communicative, verbal, non-verbal, kinetics, proxemics, visual communication, gestures, tactile communication, social zone.

\section{INTRODUCTION}

Culture plays an important role in nonverbal communication, and it is one aspect that helps to influence how learning activities are organized. In many Indigenous American Communities, for example, there is often an emphasis on nonverbal communication, which acts as a valued means by which children learn.
In this sense, learning is not dependent on verbal communication; rather, it is nonverbal communication which serves as a primary means of not only organizing interpersonal interactions, but also conveying cultural values, and children learn how to participate in this system from a young age. 
The term paralinguistic was coined in 1940 by the American linguist A.J. Brought in by Hill. As a field of study of paralinguistic, we can take a nonverbal communication. Phonetic units, facial expressions, gestures, hand gestures, and more are used directly to facilitate communication. Paralinguistic studies the impact of communication tools on the listener and the communication process, their importance in communication. Pause and intonation are also important in communication. Neuropsychologist and neurolinguist A.R. Luria points out that "in the age of humanity, the process of communication took place without sounds. It is possible to think that the first communication appeared in the process of active work, in which the communication was the result of gestures related to the same activity, and it was understood only by the participants of that process of activity. This communication referred to a specific subject or process.

The communicative process can be axial (in which the information is directed only to certain specific people) or retial (in which the information is directed to a number of probable recipients). The communicator knows how much the recipient understands him when the "communicative roles" change. Because the recipient becomes a communicator and expresses how he understood the content of the information he received from the previous communicator. The following are used as a system of signs in nonverbal communication:

- Optical-kinetic system includes gestures (hand motor skills), facial expressions (facial motor skills), pantomime (whole body motor skills). The importance of these signs in communication is so great that a separate field for their study - kinesics - has been formed.

- The paralinguistic system consists of sound vocalization, which includes sound qualities, range. The extra-linguistic system includes pauses, coughing, crying, laughing, speech tempo.

- The proxemics includes the spatial location of the participants in the communicative process and the communicative speech.

- Visual contact involves communicating through the eyes. Initially, it was thought that this type of communication could only take place within the context of intimate communication. However, recent research shows that visual contact can be observed in other areas, such as medicine, pedagogy, management, and so on.

\section{THE MAIN PART}

Nonverbal communication system plays an important role in the communication process. They complement the speech, replace it, reflect the emotional state of the participants in the communicative process.

Nonverbal means of communication include facial expressions, tone of voice, pause, pose (position), tears, laughter, and more. These tools are verbal communication - it fills, amplifies and sometimes replaces the word.

Nonverbal communication varies in different age groups. For example, children often use crying as a means to influence adults, to convey their desires and moods.

According to the classification proposed by B.F.Lomov, the functions of communication are different, for example, the informationcommunicative function.

The information-communicative function of communication is to ensure the exchange of 
information. The exchange of information takes place through various signs, systems. Usually verbal (in which speech is used as a character system) and nonverbal (in which a non-verbal character system is used) communication is distinguished.

The relevance of nonverbal means of communication to the content and purpose of verbal communication of information is a type of behavioral culture. Different tools are chosen in different age groups to implement non-verbal communication. Conformity of the means used in non-verbal communication to the purposes and content of verbal communication is an integral part of the culture of communication. Such consistency is very important for the educator, as both verbal and non-verbal means of communication are tools of professional activity.

Non-verbal communication comes in several forms:

- Kinetics (gestures, facial expressions, pantomime)

- Proxemics (distance and time criteria)

- Visual communication (through the eyes)

The system of kinetic signs consists of gestures, facial expressions and pantomime. For example, a person who speaks the truth is not afraid to show his open palms. The liar tries to cover his palms. One of the signs of high self-esteem from the interlocutor is that the whole palm is in the pocket and the thumb is sticking out. Suspicion is usually expressed by protecting the mouth with the hand, touching the nose, stroking the eyelids, scratching the back of the ear or the neck. Licking the chin, indicates difficulty in making a decision. The state of nervousness is hidden under the fact that a person repeatedly touches something - a wrist ring, a watch, etc. - without any purpose. The tendency to dominate (dominance) in a person can be felt from sitting on a chair with wide legs. Dominance is evident, especially when the protruding leg is trampling the ground with its tip. The hands on the back of the head and the fists on the waist in women also indicate a tendency to strive for dominance. Absent dust on clothing indicates that the wearer is ignoring or disagreeing with the interlocutor's opinion with such a move. If a person is sitting with his palms resting on his palms, it is a sign that he is listening and thinking.

The system of proxemic signs consists of the spatial arrangement of the participants in the communicative process. During communication, the relationship between people takes place in one of 4 different regions. In particular, only the closest and most familiar people are included in the intimate area $(15-45 \mathrm{~cm})$. Its main features are: confidence environment, low noise, tactile communication. The entry of strangers into this area causes certain physiological changes in the body. (heart rate increases, adrenaline release increases). In the personal area (45-120 $\mathrm{cm}$ ) communication of acquaintances, colleagues takes place. Its main symptoms are: longer duration of visual contact, superiority of verbal communication over nonverbal communication. In the social zone (120-400 $\mathrm{cm}$ ) there is a dialogue of strangers. Its main features are: the formal nature of the communication, the fact that the interlocutors do not know each other well. Communicates with a large group of people in a public area ( $400 \mathrm{~cm}$ or more). Its main symptoms are: lack of direct contact, increased role of nonverbal signals.

Visual contact is made through the eyes. Psychological experiments have shown that when interlocutors look into each other's eyes, they express their liking, loyalty, or readiness for aggressive reactions. During a 
conversation on an unpleasant topic, people avoid eye contact. Women are more prone to visual contact. Under the influence of a person's emotional state, the shape of the pupil changes. For example, under the influence of negative emotions, the pupils narrow, and when a positive state is observed, the pupils dilate.

According to experts advice, in order to establish a positive and trusting relationship, the interlocutors need to occupy $60-70 \%$ of the entire communication time in visual contact. If the person is not sincere or shy, visual contact takes up $1 / 3$ of the entire communication time. If visual contact takes up $2 / 3$ of the entire communication time, this condition indicates a strong interest in the person (in which the pupil dilates) or a negative attitude (in which the pupils constrict). But national features must be taken into account in visual communication. It is common in the peoples of Southern Europe to look long into the eyes of the interlocutor. To some, this may seem like an insult. The Japanese look more at the neck than at the face. Visual contact should not exceed 10 seconds. The optimal variant of visual communication is that the speakers face each other at a certain angle (9o degrees), not face to face. This positioning does not force staring and ensures freedom of movement. Hence, several character systems are used in nonverbal communication. Their use is often done unconsciously.

The functions of nonverbal communication means are:

1. Delivery of additional information. The high and low tone of the tone in expressing one's opinion represents the communication in a colorful way and serves to increase the effectiveness of the process. In addition to intonation, the use of gestures or facial expressions plays an important role in shaping the essence of the conversation.

2. To replace verbal components in communication. Expressing anger, skepticism, affirmation (hand gestures, shrugs, eyebrows) through nonverbal means and ending the thought through incomplete intonation or gestures in the process of communication.

3. Use in combination with verbal means. The participation of paralinguistic means in the communication process allows you to fully understand the essence of the conversation. For example, if the conversation continues, a melody is selected that matches the question being asked. But the specificity of the timbre remains unknown. Therefore, the type of melody is the main factor of speech, and the type of timbre chosen is the paralinguistic factor.

Speech prosody is a key factor in communication, i.e. the use of prosodic parameters during a conversation: syllable, rhythmic structure, syntagma and phrases. Another means of forming prasodic elements is intonation.

We know that intonation is the sum of the sounds of speech (volume, pitch, tone of voice). It is the intonation that helps to understand and master the meaning of the idea, to increase its diversity. Factors that form the basis of intonation: rhythm, tempo, timbre and tone.

Intonation is an important means of communication. According to E.E. Shevtsova, the importance of intonation in communication is important in understanding or distinguishing the same meaning in the ideas we are told, in understanding whether ideas are directly related or contradictory to each 
other. The intonation of a speaker depends directly on the event he is narrating, his character, temperament, and a number of other factors. Intonation also helps to understand the tag meaning in thoughts that are difficult to express in words during a conversation. Also, through intonation, the interlocutor can express his or her pain, joy, surprise, or anger. The main component of intonation is tone. During the filtering process, the tone changes according to the same situation or is chosen by the interlocutor - "the frequency of the sound changes from a constant state and adapts to the selected space, time and state."

It is in this process that we see a number of functions of intonation, namely: the division of the thought being expressed into rhythmic groups and syntagms; the connection of the parts of thought being expressed; distinguishing meaning in words; to separate the important parts of the thought being expressed; expression of emotions in words, text; to reveal the attitude of the interlocutor to the opinion he is expressing (irony, seriousness, etc.).

\section{CONCLUSION}

Only a small percentage of the brain processes verbal communication. As infants, nonverbal communication is learned from socialemotional communication, making the face rather than voice the dominant communication channel. As children become verbal communicators, they begin to look at facial expressions, vocal tones, and other nonverbal elements more subconsciously.

The relevance of nonverbal means of communication to the content and purpose of verbal communication of information is a type of behavioral culture. Different tools are chosen in different age groups to implement non-verbal communication. Conformity of the means used in non-verbal communication to the purposes and content of verbal communication is an integral part of the culture of communication. Such consistency is very important for the educator, as both verbal and non-verbal means of communication are tools of professional activity. Nonverbal communication system plays an important role in the communication process. According to some data, $80 \%$ of information is represented by gestures, facial expressions and pantomime.

The tone of the speaker's speech serves to enhance the meaning, the effectiveness, of the thought being spoken. Also, the tone chosen in the emphasis of the part of the conversation that the speaker considers important, also forms the specific character of the conversation.

Nonverbal communication systems play an important role in the communication process. According to some data, $80 \%$ of information is represented by gestures, facial expressions and pantomime. Nonverbal characters complement speech, sometimes replacing it, reflecting the emotional state of the participants in the communicative process. Therefore, it is very important to observe nonverbal signals during communication and understand their content.

\section{REFERENCES}

1. Fernando Poyatos. Paralanguage: a linguistic and interdisciplinary approach to interactive speech and sounds (1993), page 330.

2. Paul Ekman. Emotions revealed: recognizing faces and feelings to improve communication (2007), p. 193. 
3. Drobysheva, V.D. "Paralinguistic Means Of Communication"

Ekonomika I Obshchestvo V Fokuse Sovremennyx Issledovaniy: Traditsii I

Innovatsii Materialy II Mejdunarodnoy Nauchno-Prakticheskoy

Konferentsii. Under The General Editor Julinoy E.G .. 2013 Publishing House:

Obshchestvo S Ogranichennoy Otvetstvennostyu Izdatelstvo Kubik (Saratov)

4. Goziev E.G. General Psychology. Tashkent. 2002.1-2 Book.

5. Goziev E.G. Behavioral Psychology. T-2001.

6. Nemov R.S. Prkticheskaya Psikologiya Poznanie Sebya. Influence On People: Posobie Dlya Uchas-Ya-M: Gumanit.Izd.Sentr.VLADOS, 2003.

7. Babina, G.V. Practicum On Discipline Logopediya. Razdel Dysarthria [Electronic Resource]: Uchebno-Metodicheskoe Posobie / Babina

8. Gurovets, G.V. K Voprosu Diagnostics Stertoy Form Psevdobulbarnoy Dysartrii // Voprosy Logopedii / G.V.Gurovets. - M .: Prosveshchenie, 1978.

9. Krupenchuk, O.I. Rechevaya Karta Dlya Obsledovaniya Rebenka Doshkolnogo Vozrasta / O.I.Krupenchuk. - M .: Litera, 2011. G.V., Belyakova L.I., Ides R.E.- Electron. Tekstovye Dannye.-M .:

Prometheus, 2012.- 104 P.- Rejim Dostupa:Http://Www.Iprbookshop.Ru/186 oo.Html._EBS «lprbooks»

10. Martynova, R.I. Sravnitelnaya Characteristic Detey, Stradayushchix Legkimi Forms Dysartrii I Funktsionalnoy Dislaliey / Rasstroystva Rechi I Metody Ix Ustraneniya I Pod Red. S.S. Lyapidevskogo, S.N. Shaxovskoy; MGPI. M., 1975. [Electronic Resource].
URL:Http://Pedlib.Ru/Books/2/0016/2_00161.Shtml

11. Shevtsova, E.E. Texnologii Formirovaniya Intonatsionnoy Storony Rechi / E.E.Shevtsova, L.V. Zabrodna. - M .: AST: Astrel, 2009. - 222, [2] P. -(Vysshaya School)

12. Ismatullayeva N.R. The Verbal Lacunas In Chinese And Uzbek Languages (On The Example Of Grammatical And Somatic Lacunas). ACADEMICIA: An International Multidisciplinary Research Journal. Vol 10, Issue 5, May, 2020. - Pp.1696-1700. 